\title{
PROMOÇÃO DE SAÚDE DE IDOSOS INSTITUCIONALIZADOS E CRENÇAS QUANTO AO ENVELHECER: PROJETO INTERGERACIONAL
}

\section{Vivian Cristina Lederer Kratz}

Especialista em Comunicação e Psicóloga. Centro Universitário da Serra Gaúcha (FSG), Brasil.

\section{Viviana Furlanetto Manduca Schneider}

Graduação em Processos Gerenciais pela Faculdade de Tecnologia Internacional e Psicologia pelo Centro Universitário da Serra Gaúcha (FSG), Brasil.

\section{Joice Cadore Sonego}

Pós-doutorado em Psicologia pela Universidade Federal do Rio Grande do Sul. Centro Universitário da Serra Gaúcha (FSG), Brasil.

\section{Tânia Rudnicki}

Pós-Doutora em Psicologia da Saúde pelo ISPA/PT. Centro Universitário da Serra Gaúcha (FSG), Brasil.
RESUMO: Estudar qualitativamente, por meio de pesquisa empírica, método misto, delineamento quantitativo longitudinal-prospectivo e qualitativo analítico, com objetivo de verificar se uma intervenção intergeracional de troca de cartas influenciaria mudanças nos níveis de depressão em idosos institucionalizados, e modificaria crenças sobre a velhice em jovens adultos universitários. Os estudantes apresentaram redução das crenças negativas. Dos sete idosos participantes da pesquisa, cinco apresentavam sintomas depressivos antes da intervenção. Após, quatro melhoraram seu estado emocional. Os resultados indicam que a intervenção tem potencial capacidade de influenciar a modificação de crenças quanto ao envelhecer, e de reduzir os níveis de depressão em idosos moradores de ILPIs. A atividade foi ao encontro da promoção de saúde no contexto da institucionalização, promovendo reflexão, interação e preenchimento de tempo livre entre os idosos, valorizando experiências de vida. Entre os jovens, promoveram-se mudanças em concepções pré-estabelecidas e reproduzidas automaticamente, além de possibilitar reflexão a respeito desse processo, suas potencialidades e limitações.

PALAVRAS-CHAVE: Instituição de longa permanência para idosos; Depressão; Envelhecimento.

\section{HEALTH PROMOTION OF INSTITUTIONALIZED ELDERLY PEOPLE AND BELIEFS ON AGING: INTERGENERATION PROJECT}

\begin{abstract}
Current study analyzes qualitatively, through an empirical research, mixed method, longitudinal-prospective and analytic qualitative design, whether the intergenerational intervention of letter exchange influences depression levels in institutionalized elderly people and modifies beliefs on aging in young undergraduates. Five out of the seven elderly people who participated in the survey showed depression symptoms prior to intervention. Four elderly people improved their emotional status after intervention. Results show that intervention may affect beliefs on aging and reduce depression levels in elderly people living in ILPIs. Current activity aimed at health promotion within the context of institutions, enhancing discussion, interaction and time spending by elderly people, while valorizing their experiences. Changes also occurred in the undergraduates attitudes with regard to pre-established ideas. It also made possible discussions on the process, its potentialities and limitations.
\end{abstract}

KEY WORDS: Homes for the Aged; Depression; Aging. 


\section{INTRODUÇÃO}

Constituído e influenciado por mudanças complexas e não lineares, o processo de envelhecimento envolve aspectos biológicos, fisiológicos e psicossociais, não apenas relativos à idade ${ }^{1}[\ldots]$. É consenso que se trata de um processo multifatorial que atinge seu ápice na fase da velhice, esta entendida como uma etapa do desenvolvimento humano ${ }^{2}$.

Junto ao aumento da expectativa de vida e ao fenômeno mundial do envelhecimento da população, o Brasil vive ${ }^{3}$ o início de um processo de inversão da pirâmide demográfica, em função do aumento da população mais velha e redução da mais jovem, por conta também da diminuição dos nascimentos. A partir do processo de mudança dos arranjos familiares, um número cada vez maior de velhos necessita das denominadas Instituições de Longa Permanência para Idosos (ILPI) ${ }^{4}$. São estabelecimentos que atendem, de forma integral, seus utentes com diferentes graus de dependência, que já não têm como permanecer sob os cuidados da família ou morando sozinhos 5 .

O contexto institucional favorece a vivência de perdas em diversos aspectos, aumento da vulnerabilidade e quadros depressivos, que podem agravar patologias préexistentes, desencadear outras desordens psiquiátricas e perda da autonomia ${ }^{6}$. A depressão em idosos é, em geral, subdiagnosticada e subtratada, embora seja o transtorno psiquiátrico mais frequente entre pessoas nessa fase ${ }^{7}$.

A estimativa é de que cerca de $15 \%$ dos idosos apresentem sintomas depressivos, sendo a prevalência mais acentuada nas populações institucionalizadas ${ }^{8}$. Estudos brasileiros trazem uma prevalência entre $49 \mathrm{e}$ 73\% em idosos que residem em instituições de longa permanência $^{9-10}$.

É importante fomentar relações externas à instituição, facilitando o acesso ao necessário apoio social. A pobreza de relações tem sido considerada um fator de risco à saúde, causadora de tantos danos quanto o fumo, a obesidade e a pressão arterial elevada. Nesse sentido, intervenções intergeracionais surgem como uma possibilidade de oferecer aos idosos institucionalizados, interação de qualidade que transcenda o ambiente da ILPI $^{11}$
Programas intergeracionais são interações intencionais planejadas entre indivíduos de diferentes grupos etários que oportunizam o estreitamento da comunicação, compartilhamento de conhecimentos, habilidades, sentimentos e ideias, além da prática de atividades cooperativas valiosas para todos os participantes $^{12}$. Visam beneficiar jovens e velhos independentemente dos laços consanguíneos, sendo espaço para quebra de preconceitos existentes entre as faixas etárias ${ }^{13}$.

O Estatuto do Idoso $^{14: 17}$ se refere à importância da intergeracionalidade em três trechos, destacando a "viabilização de formas alternativas de participação, ocupação e convívio do idoso com as demais gerações"; nos direitos fundamentais, quando afirma, "os idosos participarão das comemorações de caráter cívico ou cultural, para transmissão de conhecimentos e vivências às demais gerações, no sentido da preservação da memória e da identidade culturais"; e no artigo 22: "Nos currículos mínimos dos diversos níveis de ensino formal serão inseridos conteúdos voltados ao processo de envelhecimento, ao respeito e à valorização do idoso, de forma a eliminar o preconceito" 14:17-18.

Entre as práticas intergeracionais já testadas e com resultados positivos, destacam-se iniciativas como a do SESC, iniciada na década de 1970 . O projeto "Era uma vez... Atividades Intergeracionais", reconhecido pela ONU, propicia entrosamento, solidariedade e afetividade entre as faixas etárias. Focado no processo educativo centrado em melhorar a comunidade e seus participantes, o trabalho intergeracional gera troca de informações, percepções e conhecimentos, em situações práticas $^{13}$.

Levando-se em conta que em ILPIs a execução de atividades conjuntas com pessoas de outras gerações é um dever a ser cumprido em conformidade com o Regulamento Técnico ${ }^{15}$ para o seu funcionamento, e pelos resultados positivos alcançados em experiências realizadas dentro e fora do Brasil ${ }^{11,16,13,17}$, um projeto intergeracional que envolva troca de cartas entre velhos institucionalizados e jovens adultos, estudantes universitários, mostra-se potencialmente promotor de saúde. 


\section{METODOLOGIA}

O estudo foi realizado com idosos $(n=7)$ residentes em duas ILPIs localizadas no interior do Rio Grande do Sul, cuja média da idade foi de 68 anos. E estudantes $(n=7)$ de um curso de psicologia de IES privada, da mesma cidade, com média de idade de 20,8 anos. A aplicação dos instrumentos, bem como a escrita das cartas, ocorreu entre abril e maio de 2017, sendo utilizado o método misto no levantamento dos dados.

A amostra foi escolhida por conveniência, intencional e heterogênea, selecionada, no caso dos idosos, a partir da aptidão cognitiva, avaliada pelo Mini Exame do Estado Mental ${ }^{18}$. Aqueles com dificuldade de visão e escrita foram auxiliados por duas das autoras do estudo. Entre os estudantes, os critérios foram ter entre 18 e 30 anos e estar nos semestres iniciais do curso (do $1^{\mathrm{o}}$ ao $4^{\mathrm{o}}$ ). Foram excluídos idosos que não obtiveram pontuação mínima no Mini Mental ou negaram participação, e estudantes fora dos critérios de idade e semestre estabelecidos.

Foi utilizada a Escala de Depressão Geriátrica - GDS, que está entre os instrumentos mais utilizados para o rastreio de depressão em idosos. A versão com 15 itens (GDS-15), validada para uso em ambulatórios gerais e ambientes não especializados, apresenta resultados satisfatórios e maior agilidade na administração ${ }^{19}$.

Utilizou-se também o Inventário de Crenças em Relação à Velhice ${ }^{20}$, escala do tipo diferencial semântica, composta de 30 itens, balizados por adjetivos opostos, validada em diversas pesquisas ${ }^{11,21}$. A intensidade das respostas é dada por um gradiente de cinco pontos em sua direção positiva ou negativa aos adjetivos presentes em cada par.

O inventário é composto de quatro domínios fatoriais: cognição, agência, relacionamento interpessoal e persona. $\mathrm{O}$ primeiro deles relacionado à cognição e capacidade de processamento de informação e soluções de problemas (10 itens); o segundo à autonomia e instrumentalização das atividades (06 itens); o terceiro a fatores afetivo-motivacionais, refletidos na interação social (07 itens); e o quarto, à imagem social do idoso (07 dos 30 itens do inventário).

A pesquisa seguiu os procedimentos éticos pautados pelas Diretrizes e Normas Regulamentadoras para Pesquisas envolvendo Seres Humanos - resolução CNS $\mathrm{n}^{\circ}$ 510, de 07 de abril de 2016, do Conselho Nacional de Saúde, aprovada por Comitê de Ética/FSG, sob $\mathrm{n}^{\mathrm{o}}$ 1.913.973. Os participantes assinaram Termo de Consentimento Livre e Esclarecido (TCLE), em que se explicam os objetivos e procedimentos do estudo, assegurando a livre escolha quanto à participação, seguindo preceitos de privacidade e confidencialidade.

PROCEDIMENTOS DE COLETA E ANÁLISE DE DADOS

A coleta de dados ocorreu em uma sala reservada em cada ILPI, equipada com mesa e cadeiras, e em uma sala de espera na instituição de ensino. No dia em que iniciou e encerrou a atividade, os idosos responderam a Escala e os estudantes o Inventário, para verificar o nível de depressão nos idosos e as crenças em relação aos idosos nos estudantes antes e depois da troca de cartas. A identificação de estudantes e idosos foi atribuída por número para cada depoente.

Foram quatro semanas de correspondências, com temas e datas pré-estabelecidos para a entrega das cartas. Os idosos iniciaram contando "Quem sou eu" ("Apresentação. De onde vim. Quem fui. O que fiz e quero fazer"), e os estudantes responderam seguindo o mesmo tema.

A segunda carta foi proposta sobre o tema "Amor e Relacionamento Interpessoal" ("As pessoas que mais amo/amei. Quem e por que são importantes para mim"). A terceira sobre "Passado, Presente e Futuro" ("O que penso sobre a vida e meu momento. $\mathrm{O}$ que vejo na velhice. O que espero para o futuro"). E a última sobre "O que ficou" ("No que as cartas me ajudaram. O que espero do meu amigo anônimo. O que mudou em mim por causa das cartas").

Os dados quantitativos foram analisados via comparação das médias encontradas nos dois grupos entre si, nos diferentes momentos da pesquisa (antes e depois da intervenção com as cartas). E a etapa qualitativa, a partir da análise de conteúdo das cartas, utilizando-se da pré-categorização dos temas propostos: "Quem sou eu", "Amor e Relacionamento Interpessoal", "Passado, Presente e Futuro" e "O que ficou", permitindo inferência, interpretação e, consequentemente, reflexão $0^{22}$. 


\section{RESULTADOS E DISCUSSÃO}

O trabalho encontrou resultados positivos resultantes da intervenção intergeracional envolvendo troca de cartas entre idosos institucionalizados e jovens universitários, influenciando na redução de níveis de depressão nos idosos e modificando crenças acerca da velhice entre os jovens adultos.

A partir da aplicação da GDS-15 (T1), identificouse a presença de sintomas depressivos em cinco dos sete idosos (ponto de corte da escala $\geq 6$ ). Na segunda aplicação (T2), apenas dois seguiam apresentando sintomas depressivos. Observa-se (Quadro 1), que dos sete participantes, quatro melhoraram seu estado emocional, o que demonstra o resultado positivo da atividade nesse aspecto. Dois permaneceram inalterados.

Uma das participantes teve o nível de depressão asseverado. No entanto, sabe-se de fatos no contexto de vida da idosa que podem ter interferido nesse resultado. Na somatória total, os participantes reduziram de 45 para 35 sua pontuação geral do estado depressivo.

Quadro 1. Pontuação da amostra - Escala de Depressão Geriátrica -15 (GDS-15)

\begin{tabular}{|c|c|c|c|c|c|}
\hline \multirow[b]{2}{*}{ Idoso } & \multirow[b]{2}{*}{ Sexo } & \multicolumn{2}{|r|}{ T1 } & \multicolumn{2}{|r|}{ T2 } \\
\hline & & Escore & Avaliação & Escore & Avaliação \\
\hline Idosa 1 & $\mathrm{~F}$ & 8 & Depressão leve & 12 & Depressão severa \\
\hline Idosa 2 & $\mathrm{~F}$ & 11 & Depressão severa & 5 & Suspeita de depressão \\
\hline Idosa 3 & $\mathrm{~F}$ & 6 & Depressão leve & 6 & Depressão leve \\
\hline Idosa 4 & $\mathrm{~F}$ & 6 & Depressão leve & 4 & Suspeita de depressão \\
\hline Idosa 5 & $\mathrm{~F}$ & 3 & Suspeita de depressão & 0 & Suspeita de depressão \\
\hline Idoso 6 & M & 8 & Depressão leve & 5 & Suspeita de depressão \\
\hline Idoso 7 & M & 3 & Suspeita de depressão & 3 & Suspeita de depressão \\
\hline Total/Média & & & $45(6,4)$ & & $35(5)$ \\
\hline
\end{tabular}

Fonte: Elaborada pelas autoras

Os estudantes mostraram incremento em termos de crenças positivas em relação à velhice (Quadro 2). Seis reduziram as crenças negativas, sendo que um as zerou. Observa-se que a estudante que não reduziu, já tinha inicialmente baixo número de crenças negativas (02).

Do total de acadêmicos, antes da atividade, apenas três tinham mais crenças positivas do que negativas em relação ao período avançado de vida. Ao final, todos apresentaram mais crenças positivas do que negativas, quanto a todos os aspectos avaliados.
$\mathrm{Na}$ somatória, os percentuais mostram que as crenças positivas aumentaram 98,6\%, enquanto as neutras reduziram $38,8 \%$ e as negativas reduziram $70,5 \%$. Tais pontuações indicam, de uma maneira geral, que a atividade foi capaz de modificar a percepção dos estudantes para melhor. Destaca-se, em alguns casos, redução acentuada de crenças negativas (de 15 para 0 , de 14 para 2, de 13 para 1) e o aumento expressivo de crenças positivas (de 2 para 28 e de 5 para 25 ). 
Quadro 2. Mudança de crenças segundo Inventário de Crenças em Relação à Velhice

\begin{tabular}{|c|c|c|c|c|c|c|}
\hline Estudante & \multicolumn{3}{|c|}{ T1 } & \multicolumn{3}{|c|}{ T2 } \\
\hline Estudante 1 & Positiva: 6 & Neutra: 9 & Negativa: 15 & Positiva: 12 & Neutra: 8 & Negativa: 10 \\
\hline Estudante 2 & Positiva: 19 & Neutra: 9 & Negativa: 2 & Positiva: 21 & Neutra: 8 & Negativa: 1 \\
\hline Estudante 3 & Positiva: 16 & Neutra: 12 & Negativa: 2 & Positiva: 28 & Neutra: 0 & Negativa: 2 \\
\hline Estudante 4 & Positiva: 2 & Neutra: 13 & Negativa: 15 & Positiva: 28 & Neutra: 2 & Negativa: 0 \\
\hline Estudante 5 & Positiva: 13 & Neutra: 10 & Negativa: 7 & Positiva: 18 & Neutra: 8 & Negativa: 4 \\
\hline Estudante 6 & Positiva: 14 & Neutra: 2 & Negativa: 14 & Positiva: 17 & Neutra: 11 & Negativa: 2 \\
\hline Estudante 7 & Positiva: 5 & Neutra: 12 & Negativa: 13 & Positiva: 25 & Neutra: 4 & Negativa: 1 \\
\hline Total/Média & $\begin{array}{c}\text { Positiva: } 75 \\
(10,7)\end{array}$ & $\begin{array}{c}\text { Neutra: } 67 \\
(9,5)\end{array}$ & $\begin{array}{c}\text { Negativa: } 68 \\
(9,7)\end{array}$ & $\begin{array}{c}\text { Positiva: } 149 \\
(21,2)\end{array}$ & $\begin{array}{c}\text { Neutra: } 41 \\
(5,8)\end{array}$ & $\begin{array}{c}\text { Negativa: } 20 \\
(2,8)\end{array}$ \\
\hline
\end{tabular}

Fonte: Elaborada pelas autoras

Comparativamente a intervenções realizadas anteriormente ${ }^{11}$, também com troca de cartas, mas entre idosos institucionalizados (10) e estudantes de ensino médio (27), os resultados são semelhantes no que se refere às modificações positivas de crenças e níveis de depressão. Enquanto neste estudo a somatória da escala de depressão reduziu de 45 para 35, na do referido estudo a queda foi mais acentuada, de 43 para 21, sendo que apenas dois idosos, do total de dez, apresentavam sintomas depressivos ${ }^{11}$.

Quanto à análise de conteúdo resultaram sete categorias, conforme é apresentado no Quadro 3:

Quadro 3. Categorias Inicias e Finais da análise de conteúdo do estudo

\begin{tabular}{|c|c|}
\hline Categoria inicial & Categoria final \\
\hline Quem sou eu & Crenças sobre a velbice \\
\hline \multirow[t]{2}{*}{$\begin{array}{l}\text { Amor e relacionamento } \\
\text { interpessoal }\end{array}$} & $\begin{array}{l}\text { Amor, alegria e outros } \\
\text { sentimentos positivos }\end{array}$ \\
\hline & Relacionamento interpessoal \\
\hline \multirow[t]{3}{*}{ Passado, presente e futuro } & $\begin{array}{l}\text { Solidão, depressão e } \\
\text { desesperança }\end{array}$ \\
\hline & Esperança e visão de futuro \\
\hline & $\begin{array}{l}\text { Sentimentos relacionados à } \\
\text { instituição }\end{array}$ \\
\hline O que ficou & $\begin{array}{l}\text { Valor da atividade, mudanças } \\
\text { e vínculo }\end{array}$ \\
\hline
\end{tabular}

Fonte: Elaborada pelas autoras

\section{CRENÇAS SOBRE A VELHICE}

Crenças pertencem ao componente cognitivo das atitudes, e juntamente com avaliações que se estruturam em generalizações e simplificações acentuadas, frequentemente conduzem a estereotipizações e preconceitos $^{23}$. Quando convidados a escrever sobre quem são, os idosos expuseram hábitos de vida e o que gostam de fazer. "Gosto de fazer meu crochê. Havia parado por conta da cirurgia, mas já estou conseguindo de novo" (Idosa, 86 anos, há 04 meses na ILPI).

Também foram mencionadas questões relacionadas à espiritualidade, descrita como importante recurso interno que contribui para a resiliência frente aos problemas ${ }^{23}$. "O padre do programa de TV que não perco por nada sempre diz que devemos nos gostar como somos, acredito muito nisso. Aceitação é importante" (Idosa, 65 anos, há 11 meses na ILPI).

O bem-estar subjetivo na velhice tem sido associado a desfechos positivos em saúde, ligando a noção de envelhecer de forma saudável a medidas subjetivas como satisfação com a vida, afetos e "disposição de espírito"24:204, o que fica evidenciado em trechos como "Sobre a velbice, o que me atrapalba mesmo é a visão, no mais tenho mobilidade e disposição para as atividades do dia a dia" (Idoso, 61 anos, 01 ano e 03 meses na ILPI) e "Cheguei na idade que cheguei e me sinto feliz por isso" (Idosa, 78 anos, 03 meses na ILPI).

Nos acadêmicos, crenças positivas também são mencionadas: "Nunca vi a velbice como algo ruim, 
muito pelo contrário, a pessoa tem que agradecer a Deus por ter chegado onde chegou e estar bem" (Estudante, mulher, 18 anos); e "Minha avó é a pessoa mais jovem de alma que eu conbeço, viaja com as amigas, faz cruzeiros, faz academia, é uma leveza que inspira" (Estudante, mulher, 22 anos).

A ambivalência permeada pelo discurso social que propaga falsos estereótipos relacionados a aspectos negativos dessa fase da vida ${ }^{2}$ também aparece no discurso: "Evito pensar sobre a velbice porque confesso ter receio" (Estudante, mulher, 22 anos). Características psicológicas, como depressão e perdas cognitivas; físicas, como doenças, dores e fragilidade; e sociais, como improdutividade e isolamento, podem levar a expressões de antipatia, discriminação, segregação e exclusão ${ }^{2}$.

\section{AMOR, ALEGRIA E OUTROS SENTIMENTOS POSITIVOS}

O compartilhamento de informações sobre a história de vida e o resgate de sentimentos prazerosos e de valorização de laços familiares e sociais, por meio de atividade intelectual, relacionam-se com conceitos como qualidade de vida na velhice e aumento da longevidade. Estimulam-se a satisfação com a vida e o senso de pertencimento à sociedade, o que colabora na percepção de autoeficácia - capacidade de organizar e executar recursos para atingir resultados - e criação de mecanismos de coping ou estratégias de enfrentamento ${ }^{11}$.

As cartas oportunizaram refletir sobre quem são e/ou foram pessoas importantes ao longo da vida. "As pessoas mais importantes da minha vida foram meu esposo, que já se foi, e minha filba. Só tenho ela" (Idosa, 65 anos, 11 meses na ILPI). "Me sinto amparada pela família, são quem eu tenbo de mais importante. Eles sempre vêm me visitar e levar para passear. Não é todo filho que faz isso pela mãe" (Idosa, 82 anos, 08 meses na ILPI). "Tive um passado muito feliz. Um marido bom, cinco filhos, que foram uma alegria, embora três falecidos" (Idosa, 86 anos, 04 meses na ILPI). Mesmo com as perdas do curso de vida, a reflexão em retrospectiva permitiu o contato com boas lembranças, gerando sensação de amparo, utilidade e valor entre os idosos. "Meu pai fez muito por mim enquanto era vivo, sempre lembro disso e sinto saudades" (Idoso, 61 anos, 01 ano e 03 meses na ILPI).

\section{RELACIONAMENTO INTERPESSOAL}

A oportunidade de interação com outras pessoas e o envolvimento social são indicadores importantes de saúde e funcionalidade entre os idosos, expressos por meio de habilidades físicas, cognitivas, emocionais e sociais ${ }^{23}$. Os idosos expressaram com quem convivem e conviveram, fazendo referência à qualidade desta interação. "Eu, meu marido e filha vivíamos sempre juntos, conversávamos, fazíamos o que tinha que fazer. Aqui tem pessoas com quem é difícil se relacionar, mas tenho várias com que converso e fazem os meus dias melhores" (Idosa, 65 anos, 11 meses na ILPI).

A valorização de familiares e amigos é citada como fator de satisfação e recurso de enfrentamento. "Tenho filbos e genros que estão sempre me agradando, quando não é um filbo é outro vindo me buscar para passear" (Idosa, 82 anos, 08 meses na ILPI). "Gosto muito quando recebo visitas" (Idoso, 61 anos, 02 anos e 08 meses na ILPI). "Minha família são meus irmãos que nunca me abandonaram e sempre me visitam. Me sentia bem quanto tinha minhas sobrinbas próximas. Aqui na casa tenbo muita estima pelo O., que sempre conversa comigo e escutamos jogo à noite" (Idoso, 61 anos, 01 ano e 03 meses na ILPI).

Com os estudantes, os laços de carinho e afeto surgiram logo nas primeiras cartas, demonstrando a capacidade da atividade de estimular esse recurso do relacionamento interpessoal positivo entre jovens adultos e idosos desconhecidos. "Você arrancou um sorriso meu dizendo que já me ama, saiba que é recíproco, tenbo um carinbo imenso por ti" (Estudante, mulher, 22 anos). Foi expressa a ligação dos estudantes com seus avós também. "Estou sempre na casa dos meus avós paternos, eles adoram" (idem). "Morro de saudades dos meus avós que moram em outra cidade, sou muito apegada a eles" (Estudante, mulher, 18 anos).

\section{SOLIDÃO, DEPRESSÃO E DESESPERANÇA}

O estado depressivo dos idosos detectado no instrumento e referido na literatura enquanto relacionado ao momento avançado de vida e às perdas envolvidas, iminência da finitude, e possível agravamento pela institucionalização, se confirma em verbalizações 
expressas nas correspondências ${ }^{6,8,9}$. "O meu maior problema é não ter com quem comentar as minhas preferências, não tenbo com quem conversar" (Idosa, 89 anos, 01 ano na ILPI). "Estou triste, pois minha vida não foi como eu quis" (Idosa, 65 anos, 11 meses na ILPI). "Meu filbo reformou toda minha casa e não pude aproveitar nada, tive que vir para cá" (Idosa, 78 anos, 03 meses na ILPI). "Desde que perdi meus filbos não durmo sem calmante" (Idosa, 86 anos, 04 meses na ILPI). Apenas um idoso não referiu expressões que envolvam depressão, solidão ou desesperança.

A qualidade de vida dos velhos institucionalizados depende de fatores como o acolhimento na instituição e o convívio com pessoas próximas. Se faz importante agir para evitar estados de solidão e isolamento, muito comuns pelo afastamento da rede de apoio social até então conhecida (família, amigos, vizinhos, trabalho, grupos comunitários, entre outros) ${ }^{25}$.

Entre os estudantes, esse tipo de expressão também se fez presente, relacionadas, especialmente ao distanciamento de um dos genitores por conta da separação dos pais. "Sinto falta de quando éramos uma família completa, apesar das inúmeras brigas que me deixavam muito triste" (Estudante, mulher, 18). "Parece que meu pai não sente falta de mim, foi minha mãe que me criou" (Estudante, mulher, 21).

O fato de ambos, idosos e estudantes, terem eventos difíceis e que geram dor e sofrimento para contar, parece ter tido potencial para aproximá-los, gerando conexão, empatia e apoio mútuo. "Espero que a senhora logo se sinta mais confortável onde está" (Estudante, mulher, 23). "A senbora é nova ainda, tem muita vida pela frente, nunca perca a esperança" (Estudante, mulher, 18). "Infelizmente a vida não é como desejamos e sonbamos, né?" (Estudante, mulher, 22). "Fiquei preocupado, pois você disse que está doente, é grave?" (Idoso, 61 anos, 02 anos, 08 meses na ILPI).

\section{ESPERANÇA E VISÃO DE FUTURO}

A carta que convidou a escrever sobre passado, presente e futuro despertou expressóes esperançosas e de satisfação com a vida entre os idosos, o que já foi denominado de "paradoxo do bem-estar na velhice" 26:354. Mesmo frente a desafios adaptativos associados ao envelhecer, fruto de fatos normativos ou não, pesquisas vêm mostrando nas últimas décadas que idosos têm experimentado afetos positivos e mantido o potencial para derivar sentido e significado, o que estaria relacionado a mecanismos motivacionais, cognitivos, emocionais e de aprendizagem ${ }^{26}$.

"Espero estar cada vez melhor, se Deus quiser, sem dor, vivendo um dia com cada filho, com meus genros que são como filbos" (Idosa, 82, 08 meses na ILPI). "Tenho que ter paciência com a recuperação da perna, pois vai melhorar. Estou fazendo fisioterapia e me esforçando" (Idosa, 86 anos, 04 meses na ILPI). "Espero ir para casa, poder ir para o bar, jogar cartas, sinuca, conversar com os antigos amigos e voltar a conviver com a família" (Idoso, 61 anos, 02 anos e 08 meses na ILPI). Essas são verbalizações que corroboram os estudos correntes e contrariam crenças ainda recorrentes que relacionam velhice com desesperança, improdutividade e isolamento ${ }^{2}$.

\section{SENTIMENTOS RELACIONADOS À INSTITUIÇÃO}

Um dos desafios que o velho enfrenta ao passar a residir em uma ILPI é a adaptação. Esse processo pode não ser bem aceito, uma vez que implica conviver com desconhecidos, dividir espaço com pessoas estranhas, depois de uma trajetória longa de convivência próxima a familiares e amigos. Tal situação costuma provocar mudanças na rotina, trazendo a necessidade da reconstrução de vínculos e ressignificação da vida ${ }^{11}$.

Expressões de receio quanto à não adaptação na ILPI permeiam o discurso dos idosos estudados. "Tinba medo de não me acostumar, mas tive que ficar. Preferia estar em casa, mas fazer o quê, a filha disse que era muito caro manter uma cuidadora" (Idosa, 65, 11 meses na ILPI). Assim como, em relação à convivência na nova realidade: "Ainda me sinto deslocada, embora o atendimento seja muito bom" (Idosa, 89 anos, 01 ano na ILPI). E de adaptação, a partir de experiências positivas quanto ao tratamento e cuidado: "Tinha medo de vir e não dar certo. Mas eles tratam bem a gente, então me 
adaptei. É bom viver aqui" (Idosa, 82 anos, 08 meses na ILPI).

A falta de atividades prazerosas também é mencionada, novamente enfatizando a importância do contato extrainstituição: "Aqui não tem muito o que fazer. O bom é quando vêm visitas" (Idoso, 61 anos, 01 ano e 03 meses na ILPI). As verbalizações expressam a dificuldade de adaptação e a relação direta do acolhimento da ILPI e do convívio com pessoas próximas para a qualidade de vida dos idosos institucionalizados ${ }^{25}$.

\section{VALOR DA ATIVIDADE, MUDANÇAS E VÍNCULO}

A interação entre gerações, quando prazerosa, pode favorecer o retardo da dependência nos velhos, possibilitando o senso de utilidade, a criatividade $\mathrm{e}$ o cuidado com os outros ${ }^{13,27}$. As cartas evidenciaram interatividade e valorização do interlocutor desde a primeira resposta, demonstrando, na maioria das relações de troca, a formação de um vínculo importante entre os participantes. "Gostei muito da sua carta e mal posso esperar pela próxima. Um abraço apertado da sua mais nova amiga" (Estudante, mulher, 23). "Gostei muito do que você contou, foi bom saber um pouco mais sobre sua vida e fico feliz em saber que é rodeada de pessoas que te amam e te fazem feliz" (Idoso, 61 anos, 01 ano e 03 meses na ILPI), ilustram a consideração.

No trabalho de auxílio na escrita e leitura das cartas junto aos idosos, pode-se notar que alguns, em especial, nutriam expectativa pela chegada da próxima correspondência, perguntando quando ia chegar, se já era dia de receber carta. O vínculo de amizade e confiança estabelecidos fica evidente quando uma idosa confidencia segredos com a estudante correspondente. "Descobrimos que minha bisnetinha será uma menina, mas ainda não posso contar para ninguém mais, só para ti" (Idosa, 82 anos, 08 meses na ILPI).

Antes de entrar no tema proposto para cada carta, a idosa recém-mencionada gostava de escrever sobre as novidades da semana, indicando o envolvimento com a atividade e com a interlocutora. Outra idosa, após o encerramento da atividade, passou a manter um caderno com escritos sobre suas preocupações, pensamentos e sentimentos, resgatando o hábito da escrita, até então deixado de lado.

Quanto às mudanças percebidas a partir da troca de cartas, encontraram-se entre os idosos expressões como "Escrever essas cartas para você e poder contar essas coisas da minha vida me deixou mais feliz, me fez bem" (Idosa, 82 anos, 08 meses na ILPI), "Foi uma oportunidade de conbecer alguém de fora da casa, isso é bom" (Idosa, 86, 04 meses na ILPI). "As cartas foram de grande ajuda, me animaram, tive momentos de descontração e fizeram com que refletisse sobre a vida" (Idoso, 61 anos, 02 anos e 08 meses na ILPI). A troca de cartas funcionou como uma rede de suporte social. O apoio advindo desta troca contribuiu para saúde mental e bem-estar psicológico, sendo estes preditores significativos de recursos pessoais de enfrentamento de problemas, inversamente correlacionados com depressão, estresse e sintomatologia física, associado à redução de riscos de mortalidade ${ }^{28}$.

\section{CONCLUSÃO}

A pesquisa mostrou que a atividade de troca de cartas entre estudantes universitários e idosos institucionalizados pode estar relacionada à redução de sintomas depressivos percebidos pelos idosos, e tem alto potencial de modificação de crenças sobre a velhice entre adultos jovens. Desta forma, configura a atividade como premissa de promoção de saúde. Oportunizou o estabelecimento de vínculos intergeracionais, promovendo reflexão sobre o senso de pertencimento, papel social, autoeficácia e significado da vida entre os idosos, além de novas concepções, aprendizado e crenças menos preconceituosas e estereotipadas entre os jovens adultos.

O trabalho mostrou ainda valor a favorecer o preenchimento do tempo livre, o resgate da escrita e a chance de contar a própria história a um interlocutor interessado e desconhecido, promovendo novas interações e contato extrainstituição para os idosos. Para os estudantes, possibilitou aproximação com a fase final de vida junto a idosos externos à própria família, trazendolhes uma visão diferente da já conhecida. Promoveu 
reflexão sobre sonhos, objetivos, vivências e angústias da sua geração, recebendo amparo e ensinamentos de quem já viveu mais do que eles e diferentes realidades de vida.

A aproximação emocional, ainda que sem aproximação física, foi capaz de propiciar confiança para o compartilhamento de informações íntimas e promover mudanças. A questão do vínculo, no que se refere ao contato das pesquisadoras com os idosos antes e durante a intervenção, é um ponto que merece atenção, já que sem essa construção fica inviabilizada a possibilidade de participação e conforto dos participantes quanto à segurança das mensagens, seu transporte, dia de entrega, o que gera muita expectativa em todos os envolvidos, mas especialmente entre os idosos que vivem na instituição. É vital que essa segurança seja garantida para não os colocar em situação de ainda mais vulnerabilidade.

Para as ILPIs, a atividade representou importante atividade de integração, trocas sociais e oportunidade de visibilidade frente a um público que, em geral, pouco conhece ou interage com essas instituições. Entre as dificuldades encontradas, além do avançado grau de comprometimento cognitivo entre os idosos institucionalizados, acarretando uma amostra reduzida em relação à intenção do estudo; estão perdas físicas como dificuldades de visão, audição e movimento das mãos, dificultando a escrita, leitura e escuta das cartas, configurando-se esses os principais desafios para o emprego desta estratégia em maior escala. Sugere-se que pesquisas futuras ampliem as amostras e aprofundem as conclusões acerca dos resultados, quem sabe reunindo e comparando dados de idosos residentes em mais ILPIs e estudantes de diferentes idades.

\section{REFERÊNCIAS}

1. OMS - Organização Mundial da Saúde. Resumo relatório mundial de envelhecimento e saúde [Internet]. Genebra, 2015.

2. Torres TL, Camargo BV, Boulsfield AB, Silva AO. Representações sociais e crenças normativas sobre envelhecimento. Ciênc. Saúde Coletiva. Rio de Janeiro, 2015 Dez. 20(12):3621-30.

3. IBGE - Instituto Brasileiro de Geografia e Estatística
(BR). Síntese de Indicadores Sociais: uma análise das condições de vida da população brasileira [Internet]. Rio de Janeiro; 2013.

4. Camarano AA, Kanso S. As instituições de longa permanência para idosos no Brasil. Rev. Bras. Estud. Popul. São Paulo, 2010 Jun;27(1).

5. Costa MCNS, Mercadante EF. O Idoso residente em ILPI (Instituição de Longa Permanência do Idoso) e o que isso representa para o sujeito idoso. Rev. Kairós Gerontol. São Paulo, 2013 Mar: PUC-SP, 16(2).

6. Carreira L. Prevalência de depressão em idosos institucionalizados. Revista Enfermagem UERJ. Rio de Janeiro, 2011; 19(2):268-73.

7. Ferreira HG, Batistoni SS. Terapia CognitivoComportamental para Idosos com Depressão. In: Freitas ER, Barbosa AJG, Neufeld CB. (Org.). Terapias Cognitivo-Comportamentais com Idosos. Novo Hamburgo: Sinopsys; 2016.

8. Siqueira GR et al. Análise da sintomatologia depressiva nos moradores do Abrigo Cristo Redentor através da aplicação da Escala de Depressão Geriátrica (EDG). Ciênc. Saúde Coletiva, Rio de Janeiro, 2009 Fev; 14(1):253-9.

9. Leal MCC, Apóstolo, JLA, Mendes AMO, Marques APO. Prevalência de sintomatologia depressiva e fatores associados entre idosos institucionalizados. Acta Paul. Enferm. São Paulo, 2014 Jun; 27(3):208-14.

10. Soares E, Coelho MO, Carvalho SM. Capacidade funcional, declínio cognitivo e depressão em idosos institucionalizados: possibilidade de relações e correlações. Rev. Kairós Gerontol. São Paulo, 2012; 15(3):117-39.

11. Piovezan M, Bessa TA, Borges FSP, Prestes SM, Chubaci RYS. "Troca de cartas entre gerações": Projeto gerontológico intergeracional realizado em uma ILPI de São Paulo. Rev. Kairós Gerontol. São Paulo, 2015 Jul-Set; 18(3):137-53.

12. Coalition MI. How to start intergerational programs in communities [Internet]. MD, USA: ERIC; 2002. 
13. França LHF, Silva AMT, Barreto MSL. Programas intergeracionais: quão relevantes eles podem ser para a sociedade brasileira? Rev. Bras. Geriatr. Gerontol. [Internet]. Rio de Janeiro, 2010;13(3).

14. Ministério da Saúde (BR). Estatuto do Idoso: Série E, Legislação de Saúde. [Internet]. 2. ed. Brasília; 2003.

15. ANVISA - Agência Nacional de Vigilância Sanitária. Resolução - RDC n. ${ }^{\circ} 283$, de 26 de setembro de 2005.

16. Silva HS, Junqueira PG. Reflexões e Narrativas (Auto) Biográficas sobre as relações intergeracionais: Resultados de uma intervenção socioeducativa com mulheres idosas. Psicologia \& Sociedade. 2013; 25(3):559-70.

17. Pontarolo R, Oliveira RC. Relações Intergeracionais na escola: relato de uma experiência. Congresso de Educação da PUCPR (EDUCERE), 2006. Curitiba: PUCPR; 2006.

18. Brucki SMD et al. Sugestões para o uso do mini exame do estado mental no Brasil. Arq. Neuro-Psiquiatr. São Paulo, 2003 Set; 61(3B):777-81.

19. Almeida OP, Almeida SA. Confiabilidade da versão brasileira da Escala de Depressão em Geriatria (GDS) versão reduzida. Arq. Neuro-Psiquiatr. São Paulo, 1999 Jun; 57 (2B):421-6.

20. Neri AL, Jorge MD. Atitudes e conhecimentos em relação à velhice em estudantes de graduação em educação e em saúde: subsídios ao planejamento curricular. Estud. Psicol. Campinas, 2006 Jun; 23(2):127-37.

21. Tarallo RS. Desenvolvimento da Versão Brasileira da Intergenerational Exchanges Attitude Scale. Campinas: Unicamp. 2015. Dissertação (Mestrado em Gerontologia), Faculdade de Ciências Médicas, Universidade Estadual de Campinas, 2015.

22. Bardin L. Análise de Conteúdo. Trad.: Luís Antero Reto, Augusto Pinheiro. São Paulo: Edições 70; 2011.
23. Neri AL. Palavras-Chave em Gerontologia. Campinas: Alínea; 2014.

24. Mantovani EP, Lucca SR, Neri AL. Associações entre significados de velhice e bem-estar subjetivo indicado por satisfação em idosos. Rev. Bras. Geriatr. Gerontol. Rio de Janeiro, 2016 Jun; 19(2):203-22.

25. Carvalho P, Dias O. Adaptação dos Idosos Institucionalizados. Millenium. Viseu: IPV, 2011 Jun; (40).

26. Batistoni SS. Saúde Emocional na Velhice. In: Freitas ER, Barbosa AJG, Neufeld CB. (Org.). Terapias Cognitivo-Comportamentais com Idosos. Novo Hamburgo: Sinopsys; 2016.

27. Erikson EH. O ciclo de vida completo. Porto Alegre: Artmed; 1998.

28. Wichmann FMA, Nunes AC, Areosa SVC, Montañés MCM. Grupos de convivência como suporte ao idoso na melhoria da saúde. Rev. Bras. Geriatr. Gerontol. Rio de Janeiro, 2013;16(4):821-32.

Recebido em: 07/12/2017 Aceito em: $17 / 06 / 2018$ 